\title{
Elevated Serum CA 125 Levels in Abdominal Tuberculosis and a Marker of Response to ATT Drugs
}

\author{
Ajaz Nabi Koul ${ }^{1 *}$ and Munir Ahmad Wani ${ }^{2}$ \\ ${ }^{1}$ Department of Medicine, Division of Infectious Diseases; Consultant Internist, \\ Sher-i-Kashmir Institute of Medical Sciences University, Srinagar, Kashmir, India \\ ${ }^{2}$ Department of General Surgery, Sher-i-Kashmir Institute of Medical Sciences University, \\ Srinagar, Kashmir, India \\ *Corresponding author
}

\begin{tabular}{|c|c|}
\hline & A B S T R A C T \\
\hline & Ascitis, abdominal mass, anemia with or without viceromegaly almost always \\
\hline Keywords & $\begin{array}{l}\text { sounds malignant until proved otherwise in any middle aged person. It holds true } \\
\text { more in a female who has high levels of CA125. } 14 \text { patients of biopsy proven }\end{array}$ \\
\hline $\begin{array}{l}\text { Tuberculosis, } \\
\text { abdominal, } \\
\text { CA125. }\end{array}$ & $\begin{array}{l}\text { abdominal tuberculosis were included in this study. In addition to routine work up } \\
\text { for tuberculosis, the serum levels of CA125 were sent before and after completion } \\
\text { of antitubercular treatment. Pre treatment levels CA } 125 \text { were in the range of } 24 \text { to }\end{array}$ \\
\hline Article Ir & $\begin{array}{l}980 \text { units with the mean of } 416.4 \text { units. The post treatment levels of } 9 \text { patients were } \\
\text { done. They ranged from } 38 \text { to } 183 \text { units with the mean of } 103.8 \text { units. The present }\end{array}$ \\
\hline $\begin{array}{l}\text { Accepted: } \\
\text { 20 November } 2016 \\
\text { Available Online: } \\
10 \text { December } 2016\end{array}$ & $\begin{array}{l}\text { case study indicated that CA125 being a tumor marker for abdominal neoplasms } \\
\text { may be elevated also in abdominal tuberculosis without gender bias. It is worth } \\
\text { mentioning that the elevated levels of CA } 125 \text { reduces significantly after treatment } \\
\text { of tuberculosis sounding resolution of infection. It may be worthwhile to find the } \\
\text { levels of CA125 in ascetic fluid and pleural fluid in suspected cases of tuberculosis. }\end{array}$ \\
\hline
\end{tabular}

\section{Introduction}

Tuberculosis is a major public health concern in developing countries especially in settings were malnutrition, poverty and illiteracy is common. Amongst them around $20 \%$ are abdominal tuberculosis. They present as ascites, hepatosplenomegaly, abdominal nodes, retroperitoneal nodes, peritoneal thickening, tubo ovarian masses, ileoceacal masses, pyrexia of unknown origin. Diagnosis is usually established by ascitic fluid analysis, ultrasound, computed tomography, GI studies, laproscopy and histopathology.
Mantoux test, ESR, gamma interferon, ADA levels, sputum for AFB, urine for AFB help in aiding the diagnosis. No single test can be presumed to be gold standard for diagnosis of abdominal tuberculosis.

In our case series we found CA125 levels varyingly elevated in patients of abdominal kochs irrespective of sex and normalization of these levels after completion of antitubercular drugs. 


\section{Materials and Methods}

The present study was undertaken in department of infectious diseases, SKIMS, Kashmir from July 2014 to July 2016. 14 cases of biopsy proven abdominal tuberculosis were included in this study. These patients were investigated, radiologic procedures were performed and ultimately subjected to laproscopy with biopsy of relevant areas.

In addition to above investigations CA 125 levels were sent before starting ATT. Patient were followed for 6 months and clinical response was documented. After stopping the drugs samples were sent for CA125 levels again and then compared.

\section{Results and Discussion}

A total of 14 patients with biopsy proven isolated abdominal tuberculosis were included in this study. Out of 14 patients 6 were males $(43 \%)$ and 8 were females(57\%), and age ranged from 24 to 52 years with mean of 38.57 years. $61 \%$ patients presented with fever and abdominal distension and rest presented with anorexia, weight loss, back ache, sweating and abdominal pain. Patients were diagnosed late due to smoldering nature of abdominal tuberculosis. The symptom duration ranged from 3 weeks to 2 years with mean duration of 6 months.

Laboratory parameters revealed mean $\mathrm{Hb}$ of $10.5 \mathrm{mgm} / \mathrm{dl}$, mean TLC of $6.2 \mathrm{k}$, with granulocytes of $70.6 \%$ and lymphocytes of $18.1 \%$. Mean serum protein was 6.9 $\mathrm{mgm} / \mathrm{dl}$, mean albumin of $3.3 \mathrm{mgm} / \mathrm{dl}$ and mean ESR of $37.8 \mathrm{~mm}$.

Mantoux test was positive in 3 patients only. Ascites was seen in 9 patients and analysis of ascetic fluid revealed predominantly lymphocytic exudative fluid with mean ADA of 62 units. AFB staining was positive in 1 patient, AFB culture was positive in same patient after 4 weeks of routine LJ incubation. PCR MTB was positive in 3 patients.

USG findings were recorded as follows

1. ascites in 9 patients

2. splenomegaly in 2 patients

3. mesenteric lymphadenopathy in 6 patients

4. bulky ovaries in 2 patients

5. omental thickening in 1 patient.

$\mathrm{CT}$ abdomen was done in all patients which confirmed the findings of ultrasound and gave following additional information

1. illeocaecal thickening in 1 patient

2. retroperitoneal nodes in 8 patients

3. peripancreatic node in 2 patients

4. hydrosalpinx in 1 patient

5. loculated pelvic ascites in 2 patients

6. omental stranding in 3 patients

7. nodular peritoneal deposits in 1 patient

Colonoscopy was done in 2 patients for microcytic hypochromic anaemia which revealed ulcerative obstructive lesion in caecum and ascending colon. The histopathology of the lesions revealed gaint cells with caseous necrosis. One patient had smear for AFB positive. This patient was on ATT and developed features of intestinal obstruction. Patient underwent laprotomy with resection and anastomosis as definitive procedure.

CA125 was done in all the patients. It ranged from 24 units to 980 units with mean of 416.4 units. The samples were repeated after completion of ATT except in 5 patients. The levels ranged from 38 units to 183 units with mean of 103.8 units. 
All these patients underwent laproscopy to establish the cause of lymphocytic exudative ascites with high CA125 levels. The 2 patients who underwent colonscopy did not undergo laproscopy and were put on ATT after analyzing colonic biopsy.

The laproscopic findings were,

1. tubercular nodules over gut and

peritoneum in 10 patients

2. adhesions in 3 patients

3. ascites in 10 patients

4. tubercules on omentum in 4 patients

5. omental thickening in 3 patients

6. Mesenteric lymphadenopathy in 6 patients.

All patients were screened for pulmonary tuberculosis and non of them was having evidences of concomitant pulmonary tuberculosis or at any other site.

CA 125 is a high-molecular-weight glycoprotein recognized by a monoclonal antibody (OC 125). It has 11,000 amino acids in its proteinaceous core and has been termed Muc16 (Davelaar et al., 1998).

Ca 125 levels are elevated in ovarian neoplasms, pancreatic tumours, lymphomas, colonic cancers, polyposis coli, pelvic inflammatory diseases, inflammatory bowel diseases, cirrhosis, pregnancy and various other benign disorders. It has been found to be elevated in diseases involving visveral surfaces (Sturgeon et al., 2008; Yin et al., 2001).

In patients with tuberculosis especially involving peritoneum the levels of CA125 are disproportionately high which tend clinicians to arrive at diagnosis of ovarian or other malignancies as compared to tuberculosis. It is vivid from present study that patients diagnosed with abdominal tuberculosis have elevated levels of CA125.
The values vary disproportionately higher depending upon site of involvement of abdomen.

It is worth mentioning that CA125 levels were increased in those patients also who had tubercular ascites with borderline ADA levels. Patients with isolated retroperitoneal lymphadenopathy had marginally elevated CA125 levels.

There have been reported cases of abdominal pathology with raised CA125 levels which were suspicoiuos of ovarian or malignant nature but proved to be tubercular in origin. These patients were put on anti tubercular treatment and followed with resolution of symptoms, signs and normalization of CA125 levels (Uzunkoy et al., 2004; Thakur et al., 2001; Tan et al., 2009).

It is advocated that except biopsy no test can be said to be sine quo non of tuberculosis but it may be attributed that CA125 is not indicator for malignancy and it can be added to the basket of non invasive tests for diagnosis of tuberculosis.

It is pertinent to mention here that serum levels of CA125 can be monitored for documentation of response. It is not possible to document response by rebiopsy or ADA levels as is possible in pulmonary tuberculosis to test sputum AFB for documenting response.

\section{References}

Davelaar, E.M., van Kamp, G.J., Verstraeten, R.A., Kenemans, P. 1998. Comparison of seven immunoassays for the quantification of CA 125 antigen in serum. Clin. Chem., 44(7): 1417-22. 
Devi, L., Tandon, R., Goel, P., Huria, A., Saha, P.K. 2012. Pelvic tuberculosis mimicking advanced ovarian malignancy. Trop. Doct., 42(3): 144146.

Oge, T., Ozalp, S.S., Yalcin, O.T., Kabukcuoglu, S., Kebapci, M., Arik, D., Isikci, T. 2012. Peritoneal tuberculosis mimicking ovarian cancer. Eur. J. Obstet. Gynecol. Reprod. Biol., 162(1): 105-108.

Sturgeon, C.M., Duffy, M.J., Stenman, U.H., Lilja, H., Brunner, N., Chan, D.W. 2008. National Academy of Clinical Biochemistry laboratory medicine practice guidelines for use of tumor markers in testicular, prostate, colorectal, breast, and ovarian cancers. Clin. Chem., 54(12): e11-79.

Tan, O., Luchansky, E., Rosenman, S., Pua, T., Azodi, M. 2009. Peritoneal tuberculosis with elevated serum $\mathrm{Ca}$ -
125 level mimicking advanced stage ovarian cancer: a case report. Arch. Gynecol. Obstet., 280: 333-5.

Thakur, V., Mukherjee, U., Kumar, K. 2001. Elevated serum cancer antigen 125 levels in advanced abdominal tuberculosis. Med. Oncol., 18: 289-91.

Uzunkoy, A., Harma, M., Harma, M. 2004. Diagnosis of abdominal tuberculosis: experience from 11 cases and review of the literature. World $J$. Gastroenterol., 10: 3647-9.

Yin, B.W., Lloyd, K.O. 2001. Molecular cloning of the CA125 ovarian cancer antigen: identification as a new mucin, MUC16. J. Biol. Chem., 276(29): 27371.

Zaidi, S.N., Conner, M. 2001. Disseminated peritoneal tuberculosis mimicking metastatic ovarian cancer. South Med. J., 94: 1212-4.

\section{How to cite this article:}

Ajaz Nabi Koul and Munir Ahmad Wani. 2016. Elevated Serum CA 125 Levels in Abdominal Tuberculosis and a Marker of Response to ATT Drugs. Int.J.Curr.Microbiol.App.Sci. 5(12): 650-653. doi: http://dx.doi.org/10.20546/ijcmas.2016.512.072 